\title{
Planejamento estratégico em empresas de engenharia civil no Maranhão: Análise das principais metodologias utilizadas
}

\author{
Strategic planning in civil engineering companies in Maranhão: Analysis of the main methodologies \\ used
}

Planificación estratégica en empresas de ingeniería civil en Maranhão: Análisis de las principales metodologías utilizadas

Thaynara Bringel da Cruz

ORCID: https://orcid.org/0000-0001-9791-0841 Universidade Federal do Maranhão, Brasil E-mail: thaynara.bringel@discente.ufma.br

Victor de Aquino Silva Gomes ORCID: https://orcid.org/0000-0002-9565-9443 Universidade Federal do Maranhão, Brasil E-mail: victor.aquino@discente.ufma.br Fábio Dieguez Barreiro Mafra ORCID: https://orcid.org/0000-0002-9481-1546 Universidade Federal do Maranhão, Brasil E-mail: fabio.dbm@ufma.br

\begin{abstract}
Resumo
Devido às mudanças no cenário econômico, de crescimento e momentos de crise financeira, observou-se grandes transformações na gestão das empresas, ou seja, acentuou-se a competitividade e o mercado tornou-se mais criterioso, passando a exigir empresas mais inovadoras, eficientes, eficazes e versáteis. Diante disso, a presente pesquisa tem como objetivo realizar um estudo sobre as principais metodologias de planejamento estratégico utilizados pelas empresas de engenharia civil no estado do Maranhão, bem como em seus empreendimentos. Para a realização deste estudo, elaborouse uma revisão bibliográfica sobre planejamento estratégico e foi criado e aplicado um questionário em algumas empresas de engenharia civil do estado. Foi observado que todas as empresas entrevistadas realizam o planejamento estratégico com a participação de funcionários qualificados e experientes e, ainda realizam a revisão dos métodos pelo menos uma vez por mês, além de difundir as decisões tomadas aos mais diversos setores da empresa. Além disso, foi possível concluir que cada empresa tem seus próprios métodos de planejamento estratégico.
\end{abstract}

Palavras-chave: Planejamento estratégico; Metodologias; Engenharia civil.

\begin{abstract}
Due to changes in the economic scenario, growth and moments of financial crisis, there were major changes in company management, that is, competitiveness was accentuated and the market became more discerning, demanding more innovative, efficient companies, effective and versatile. Therefore, this research aims to conduct a study on the main strategic planning methodologies used by civil engineering companies in the state of Maranhão, as well as in their enterprises. To carry out this study, a literature review on strategic planning was prepared and a questionnaire was created and applied in some civil engineering companies in the state. It was observed that all the companies interviewed carry out strategic planning with the participation of qualified and experienced employees, and also review the methods at least once a month, in addition to disseminating the decisions taken to the most diverse sectors of the company. Furthermore, it was possible to conclude that each company has its own strategic planning methods.
\end{abstract}

Keywords: Strategic planning; Methodologies; Civil engineering.

\section{Resumen}

Debido a cambios en el escenario económico, crecimiento y momentos de crisis financiera, se produjeron cambios importantes en la gestión empresarial, es decir, se acentuó la competitividad y el mercado se volvió más exigente, demandando empresas más innovadoras, eficientes, eficaces y versátiles. Por lo tanto, esta investigación tiene como objetivo realizar un estudio sobre las principales metodologías de planificación estratégica utilizadas por las empresas de ingeniería civil en el estado de Maranhão, así como en sus empresas. Para la realización de este estudio se elaboró una revisión de la literatura sobre planificación estratégica y se elaboró y aplicó un cuestionario en algunas empresas de ingeniería civil del estado. Se observó que todas las empresas entrevistadas realizan una planificación estratégica con la participación de empleados calificados y experimentados, y también revisan los métodos al menos una vez al mes, 
además de difundir las decisiones tomadas a los más diversos sectores de la empresa. Además, se pudo concluir que cada empresa tiene sus propios métodos de planificación estratégica.

Palabras clave: Planificación estratégica; Metodologías; Ingeniería civil.

\section{Introdução}

De acordo com Pereira (2011), o processo de planejamento iniciou-se formalmente entre 1903 e 1916, quando Taylor, que desenvolveu a Administração Científica (Taylorismo), e Fayol começaram os primeiros estudos sobre Administração. E, nessa época, a Administração era compreendida apenas como a utilização de critérios racionais e padronizados para dividir as tarefas, sem levar em conta as reais funções dos funcionários no conjunto da empresa.

O Planejamento Estratégico tem como foco elaborar estratégias que resultem no cumprimento das metas e objetivos estabelecidos (Teixeira, et al., 2015) e, também, como afirma Oliveira (2007, p.38), “o planejamento estratégico não deve ser considerado apenas como uma afirmação das aspirações de uma empresa, pois inclui também o que deve ser feito para transformar essas aspirações em realidade". Este teve sua origem na década de 1960, visto como um aperfeiçoamento das técnicas de planejamento de longo prazo e de orçamentação e, nessa década, as grandes empresas passaram a implementar o planejamento estratégico de maneira formal, técnica e apresentando a responsabilidade praticamente aos líderes da corporação (Mendes, 2015).

De acordo com Chagas (2008), o líder é responsável por utilizar o planejamento como suporte para sua administração, pois "não adianta remar quando não se sabe o rumo". Deve-se então, identificar e solucionar as causas dos problemas existentes na organização. Chagas (2008), também afirma que as maiores incidências são durante o projeto escopo, projeto construtivo e execução dos serviços, desse modo a empresa e os empreendimentos passam a ter mais sucesso, com um planejamento bemfeito.

De acordo com Alday (2000), empresas com as mais diferentes características estão dando atenção sistemática à estratégia, sejam elas pequenas, médias, grandes, distribuidores ou fabricantes, pois todos os tipos de organizações devem estabelecer os caminhos adequados de acordo com seus objetivos. Com isso, evidencia-se o crescimento do Planejamento Estratégico, que ocorreu principalmente, devido às mudanças repentinas nos ambientes da organização, seja econômico, social, tecnológico ou político, desse modo, a empresa somente irá prosperar se conseguir organizar e ajustar as situações (Alday, 2000).

De acordo com a Norma ABNT NBR ISO 9001 - Sistema de gestão da qualidade (2015), a adoção de um sistema de gestão da qualidade é uma decisão estratégica para uma organização que pode ajudar a melhorar seu desempenho global e a prover uma base sólida para iniciativas de desenvolvimento sustentável, trazendo benefícios como: capacidade de prover constantemente serviços e produtos que atendam aos requisitos dos clientes, aumentar a satisfação do cliente, abordar riscos e oportunidades associados com seus objetivos e a capacidade de demonstrar conformidade com requisitos especificados de sistemas de gestão e qualidade.

Diante do exposto, foi possível observar que nas décadas passadas o planejamento estratégico já fazia parte de empresas de diversos setores, porém no ramo da engenharia civil teve dificuldades de implementar tais processos, como afirma Freitas (2014), o pensamento empresarial na engenharia civil é caracterizado por uma cultura centrada em uma visão muito mais operacional do que tática e estratégica e muitas empresas ainda encontram dificuldades na implementação de um sistema de planejamento.

Com isso, o setor da Engenharia Civil, devido às mudanças do cenário econômico, de crescimento e momentos de crise financeira, demandou grandes mudanças na gestão das empresas desse ramo. Quanto ao crescimento econômico, acentuou-se a competitividade, pois o mercado tornou-se mais criterioso, passando a exigir empresas mais inovadoras, eficientes, eficazes e versáteis. E em relação aos momentos de crise, muitos fatores exigiram mais atenção dos administradores, alertando assim sobre o uso e o aperfeiçoamento do planejamento. Dessa forma, é importante analisar como as empresas estão implementando o planejamento estratégico. 
De acordo com Rotilli (2012), um projeto em qualquer área e, principalmente, na Engenharia Civil, exige um planejamento com antecedência para que se tenha sucesso. Em um empreendimento, inúmeros são os aspectos envolvidos: custo, tempo, mão de obra, materiais, suprimentos, dentre outros. Esses aspectos demandam planejamento, controle, ações e avaliação do que foi realizado, para que se tenha um desempenho adequado e melhora dos processos. Ou seja, o planejamento é uma forma de diminuir os riscos e otimizar os resultados, por meio do estabelecimento de objetivos, metas, prazos e formas para alcançar os objetivos (Rotilli, 2012). Dessa forma, é perceptível a necessidade de compreender as principais metodologias utilizadas quanto ao planejamento estratégico dos empreendimentos.

É possível observar que os investimentos em gestão e controle aumentaram no âmbito da Engenharia Civil. As empresas passaram a buscar aumento da produtividade, redução das perdas e controle da qualidade. Assim, o Planejamento Estratégico tornou-se fundamental para as organizações que almejam negócios mais eficientes, lucrativos e sucesso em seus empreendimentos, porém ainda há dificuldades em encontrar estudos relacionados a planejamento estratégico em empresas do ramo da Engenharia Civil. Diante disso, a presente pesquisa tem como objetivo realizar um estudo sobre os principais métodos de planejamento estratégico utilizados pelas empresas de Engenharia Civil no estado do Maranhão, bem como em seus empreendimentos. Para a realização deste estudo, elaborou-se uma revisão bibliográfica sobre planejamento estratégico, foi criado e aplicado um questionário em algumas empresas do estado, a fim de coletar dados sobre os seus processos de planejamento. Após isso, foram expostos e analisados os dados obtidos.

\section{Revisão da Literatura}

\subsection{Planejamento estratégico}

De acordo com Teixeira et al. (2015), o Planejamento Estratégico é como uma ferramenta de gestão, sendo um dos pontos essenciais para adequar problemas encontrados nas organizações, ele aponta as medidas positivas que uma empresa deve tomar para enfrentar ameaças e aproveitar as oportunidades encontradas em seu ambiente.

Planejamento estratégico é o processo administrativo que disponibiliza apoio metodológico para as organizações, para que essas escolham o melhor caminho a seguir, interagindo com os elementos externos e atuando de forma revolucionária e diferenciada (Oliveira, 2018). E, de acordo com Rigby (2009), o Planejamento Estratégico disponibiliza um processo metodológico para analisar as questões críticas, principalmente medidas de grande impacto e comprometimento da empresa.

O planejamento é a função gerencial que define os objetivos a serem alcançados e os meios necessários para atingi-los. É a função que liga o presente ao futuro. Quando o planejamento se volta para a organização e é utilizado para estabelecer seus direcionamentos futuros, ele é chamado de planejamento estratégico (Mendes, 2015, p.11)

De acordo com Oliveira (2018), o planejamento estratégico tem três dimensões operacionais: delineamento, elaboração e implementação. O delineamento trata da estruturação do processo, através da escolha sistemática, assim como o profissional que ajudará neste delineamento. A elaboração compreende o seguimento das fases e etapas do Planejamento Estratégico, que será disposta a seguir. Já a implementação inclui assuntos organizacionais, informações, orçamentos, incentivos, treinamentos e competências necessárias para o desenvolvimento do processo.

Ribas et al. (2014), reforça esta constatação de Oliveira (2018), quando afirma que, o processo de planejar compreende três etapas principais: a definição de objetivos, no qual é escolhido o objetivo principal, que depende do tipo de dificuldade, do tipo de oportunidade e da disponibilidade de recursos; a definição dos meios de execução, que expõe a estratégia e os meios de alcançá-la; e a definição dos meios de controle, que consiste em acompanhar a execução das atividades e o grau de realização dos objetivos.

Segundo Oliveira (2018), Planejamento Estratégico possui quatro fases e cada fase com suas etapas, conforme 
apresentado na Figura 1, a seguir:

Figura 1 - Fases do planejamento estratégico.

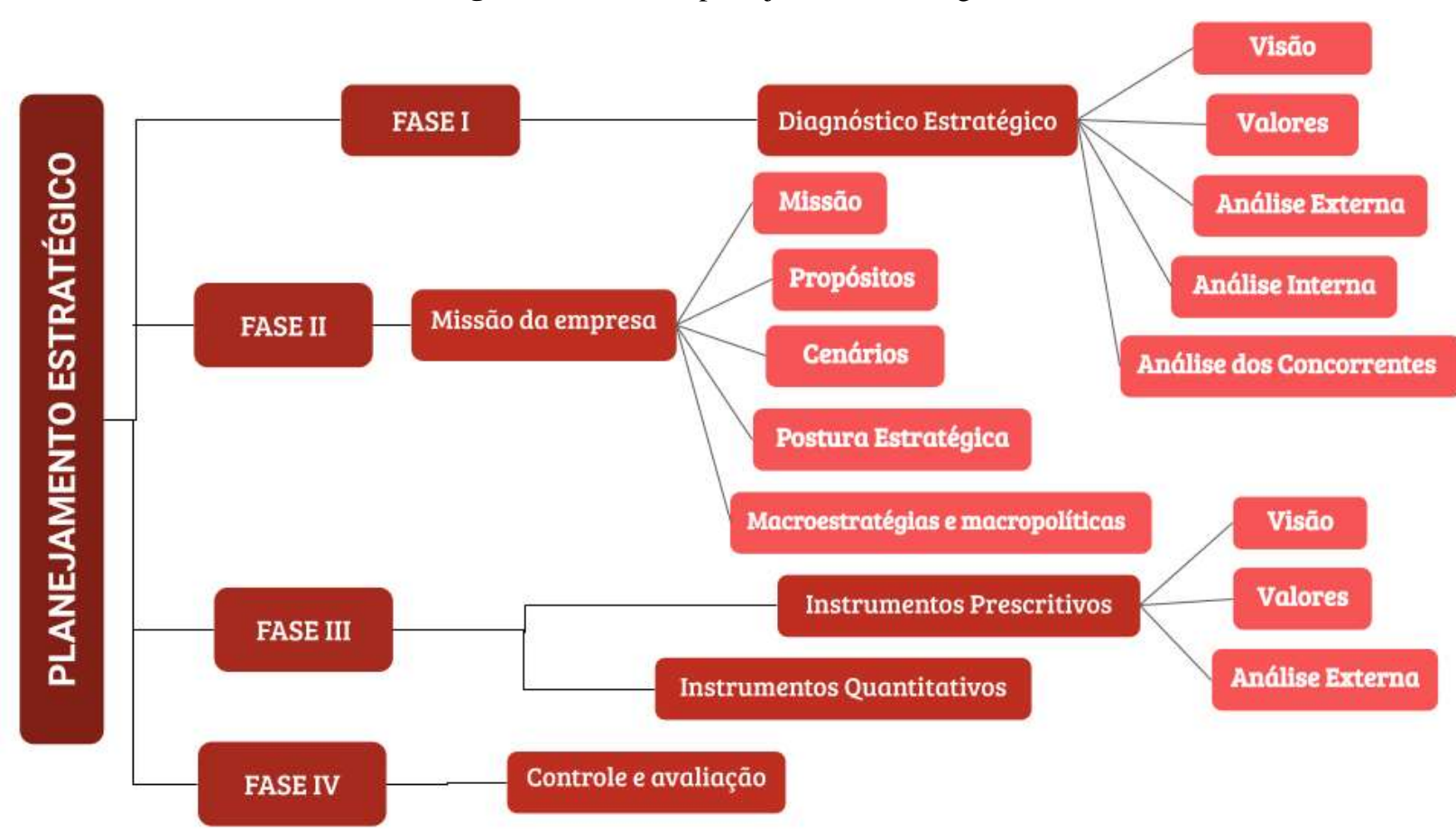

Fonte: Oliveira (2018). Adaptado.

Nos tópicos seguintes serão apresentadas as fases do projeto de acordo com a classificação de Oliveira (2018).

\subsubsection{Diagnóstico estratégico}

No ambiente de incertezas, no qual as empresas estão inseridas, torna-se importante o conhecimento das variáveis internas e externas que afetam a organização, para analisar a posição em que se encontra e traçar o futuro desejado. Então, uma ferramenta eficaz nessa tarefa e que pode trazer resultados interessantes para a empresa é o diagnóstico estratégico (Francisco, et al., 2011).

De acordo com Oliveira (2018), essa fase determina "como está" a empresa. Ela é realizada através de pessoas específicas que analisam e verificam todos os aspectos característicos da empresa.

Diagnóstico Estratégico analisa o que não se consegue observar facilmente, analisa desde os elementos da estrutura de poder da organização, o clima organizacional, até as expectativas da empresa e sua cultura. Assim, caso a conclusão seja de sucesso com o processo, ele inicia-se. (Pereira, 2002).

De acordo com Oliveira (2018), essa fase é decomposta em cinco etapas básicas:

I. Identificação da visão: verificam-se as expectativas e desejos que os principais responsáveis pela empresa almejam dentro de um período mais longo e uma abordagem mais ampla. Assim, a visão representa o que a empresa aspira em breve ou distante;

II. Identificação dos valores: identifica-se o conjunto de princípios, crenças e questões éticas fundamentais de uma organização, como forma de sustentar suas principais decisões. Assim, o adequado reconhecimento e disseminação desses valores influencia na qualidade da elaboração do planejamento estratégico na empresa;

III. Análise externa: verificam-se as ameaças e oportunidades no ambiente da empresa e identifica as melhores formas de dificultar ou aproveitar tais situações. Deve-se analisar: o mercado regional, nacional e internacional, 
as evoluções tecnológicas, fornecedores, aspectos socioeconômicos, políticos e culturais, mão de obra, concorrentes etc. Nessa etapa, divide-se o ambiente da empresa em duas partes: ambiente direto, conjunto de elementos que a empresa identifica e avalia a maneira mais efetiva e adequada; e ambiente indireto, que é o conjunto de elementos que a empresa identificou, mas não tem condições de avaliar ou medir o grau de influência entre a empresa e seu ambiente;

IV. Análise interna: verifica-se os pontos fortes, fracos e neutros da organização. Os primeiros é o diferencial da empresa, os pontos fracos são acontecimentos que podem vir a prejudicar a empresa. E determinam ponto neutro quando não há condições de caracterizar se em dada prática ou aspecto têm-se benefícios ou prejuízos. Para o estabelecimento desses pontos, analisa-se a estrutura organizacional, sendo esse um dos principais atributos. Além disso, alguns outros fatores devem ser considerados nessa análise: produtos e serviços atuais, novidades, promoções, tecnologia, suprimentos, estilo de administração, resultados empresariais, recursos financeiros/finanças, controle, avaliação etc.;

V. Análise dos concorrentes: é um aspecto da análise externa, que deve ser detalhado para que se identifique vantagens competitivas da própria organização e dos concorrentes.

\subsubsection{Missão da empresa}

Oliveira (2007, p.107) afirma: "Missão é a razão de ser da empresa. Nesse ponto procura-se determinar qual o negócio da empresa, porque ela existe, ou, ainda, em que tipos de atividades a empresa deverá concentrar-se no futuro". A missão representa o negócio da empresa, define, assim, o ramo que ela irá atuar e é ela que comunica o propósito da organização tanto interna, quanto externamente (Pereira, 2002).

De acordo com Lima (2009), na Fase II, identifica-se a missão, os propósitos, os cenários, a postura estratégica e as macroestratégias e macropolíticas. Essas etapas serão base para a decisão de como a empresa deverá ser, qual imagem irá transmitir, quais valores seus serviços terão e qual será o futuro cenário da organização, como se preparar para eles. Assim, para melhor conexão da empresa, a postura estratégica, as macroestratégias e macropolíticas devem ser seguidas por todos.

De acordo com Oliveira (2018), essa fase é dividida, de forma conceitual e genérica, em cinco etapas:

I. Estabelecimento da missão da empresa: determina-se o causador principal da existência da empresa, isto é, "quem a empresa atende".

II. Estabelecimento dos propósitos atuais e potenciais: relaciona-se ao implemento da missão de forma mais ampla, envolvendo toda a organização. Oliveira ratifica:

Propósitos são compromissos que a empresa se impõe no sentido de cumprir sua missão. Representam grandes áreas de atuação selecionadas no contexto da missão estabelecida. Correspondem à explicitação de posições ou áreas de atuação planejadas para toda a empresa, devidamente aceitas por seus acionistas e executivos como desejáveis e possíveis. (Oliveira, 2007, p.110);

III. Estruturação e debate de cenários: elaboração de critérios e medidas para a organização da empresa, ou seja, composição do cenário futuro da empresa, que devem ser elaborados com base nos dados e informações gerados pelo Sistema de Informações Estratégicas (SIE).

IV.Estabelecimento da postura estratégica: escolher uma das alternativas de caminho, sendo essa a maneira mais adequada para a empresa cumprir sua missão, observando a situação característica da empresa, que foi estabelecida no diagnóstico estratégico. 
V. Estabelecimento das macroestratégias e macropolíticas: para o primeiro, estabelecer grandes ações ou condutas para que a empresa possa ter sucesso e vantagens no ambiente; E, para macropolíticas, estabelecem-se grandes direções que servirão de apoio para as decisões da empresa, para que ela melhor interaja com o ambiente. Em suma, ambas correspondem às grandes orientações estratégicas da empresa.

\subsubsection{Instrumentos prescritivos e quantitativos}

Alguns autores como Ribas et al. (2014), definem essa etapa como as atividades que envolvem o investimento de energia e recursos, no qual algumas são padronizadas e integram os procedimentos e outras atividades precisam ser definidas uma a uma, quando é necessário colocar em prática uma decisão não programada. De forma geral, essa etapa termina quando o objetivo é atingido.

De acordo com Oliveira (2007), essa fase determina "de onde se quer chegar" e de "como chegar na situação que se deseja" e divide-se em dois instrumentos relacionados:

Instrumentos prescritivos: descreve o que deve ser executado pela organização para que alcance sua missão, de acordo com o que foi estabelecido na Missão da empresa e de acordo, também, com a visão. É realizado através de etapas:

I. Estabelecimento de objetivos, desafios e metas: estabelecer o que se quer alcançar, estabelecer uma realização que deve ser constantemente perseguida e estabelecer as etapas para o cumprimento dos objetivos, definindo prazos para se alcançar;

II. Estabelecimento de estratégias e políticas funcionais: estabelecer uma alternativa mais adequada para alcançar o objetivo, o desafio e a meta e, também, estabelecer níveis de delegação, faixas de valores e/ou quantidades limites, parâmetros ou orientações para a tomada de decisões (geralmente por área funcional) e alcance dos objetivos;

III. Estabelecimento dos projetos e planos de ação: estabelecer trabalhos que devem ser executados com responsabilidade e o conjunto desses projetos homogêneos são chamados de programas e estabelecer as partes comuns dos diversos projetos.

Instrumentos quantitativos: são projeções econômico-financeiras do planejamento orçamentário, necessários para elaborar os planos de ação, projetos e atividades previstas. E analisa-se quais são os recursos indispensáveis e quais as expectativas para atingir os objetivos, desafios e metas da empresa.

\subsubsection{Controle e avaliação}

De acordo com Ribas et al. (2014), ao final do processo de planejamento, está a definição dos meios para verificar se os objetivos estão sendo realizados, a função da avaliação, consiste em acompanhar a execução das atividades e o grau de realização dos objetivos, controlando as estratégias definidas no processo de planejamento.

De acordo com Oliveira (2018), nessa fase analisa-se "como a empresa está indo". Controle é a ação necessária para alcançar os objetivos, desafios, metas, estratégias e projetos estabelecidos. Nesta quarta fase, deve-se considerar uma situação adequada de custos versus benefícios e é aconselhável que o controle e a avaliação sejam realizados passo a passo no desenvolvimento do planejamento estratégico.

Essa fase envolve alguns processos: estabelecimento e análise de indicadores de desempenho, avaliação de desempenho, comparação do desempenho real com os objetivos, desafios, metas, projetos, planos de ação estabelecidos, análise dos desvios dos objetivos, tomada de ação corretiva provocada pelas análises efetuadas, acompanhamento para avaliar a eficiência e eficácia da ação de natureza corretiva e adição de informações ao processo de planejamento, para desenvolver os ciclos futuros da atividade administrativa. 


\section{Metodologia}

\subsection{Classificação da pesquisa}

Com a intenção de conhecer o atual cenário da Engenharia Civil no estado do Maranhão e alcançar o objetivo proposto, principalmente sobre as diversas formas de planejamento estratégico adotados por empresas de Engenharia Civil do estado, escolheu-se a metodologia de pesquisa de campo junto ao mercado, com uma abordagem quantitativa, pois demonstrou em números as opiniões, e qualitativa, que identificou dados que não podem ser mensurados numericamente. E, por fim, foram analisados os dados em conjunto.

A pesquisa bibliográfica segundo Marconi e Lakatos (2003), é todo estudo já tornado público em relação ao tema estudado, em forma de livros, revistas, monografias, teses, artigos e onde mais se puder ter acesso. A sua finalidade é fazer com que o pesquisador entre em contato direto com tudo o que foi escrito sobre determinado assunto, o auxiliando na obtenção de informações e na análise de suas pesquisas.

Logo, esta pesquisa, quanto aos procedimentos técnicos, é classificada como um estudo do tipo levantamento de dados, pois realizou entrevistas com profissionais de algumas empresas de Engenharia Civil. Quanto aos objetivos, classifica-se como uma pesquisa exploratória e descritiva, pois também compreende um estudo bibliográfico sobre o tema, a fim de conhecer e aprofundar sobre $\mathrm{o}$ assunto.

A metodologia aplicada na pesquisa seguiu as etapas demonstradas a seguir na Figura 2:

Figura 2 - Metodologia aplicada.

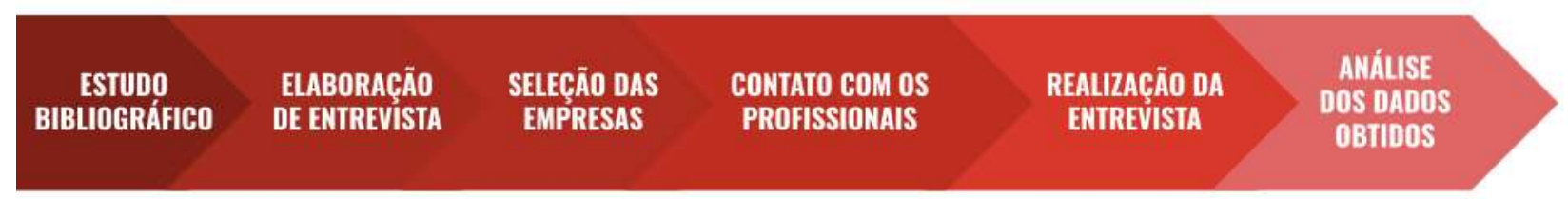

Fonte: Autores (2021).

Como é possível observar na figura 2, este trabalho iniciou-se por uma pesquisa bibliográfica dos principais conceitos e processos envolvidos nas diversas correntes do Planejamento Estratégico, consultou-se várias literaturas relacionadas com o objetivo de adquirir um entendimento mais amplo sobre o assunto.

A principal ferramenta de coleta foi um questionário, que foi aplicado por meio de entrevistas a profissionais de algumas empresas de Engenharia Civil que atuam no Maranhão. Assim, houve a contatação de profissionais, pelo menos um de cada empresa, para a realização das entrevistas, sendo esses conhecedores sobre as metodologias utilizadas para a realização e implementação do planejamento estratégico. A tabulação dos dados, seu tratamento e a confecção dos gráficos foram realizados no Excel e em planilha eletrônica do Google Forms. E, por último, teve-se a análise dos dados obtidos.

\subsection{Resumo do questionário}

O questionário apresenta inicialmente perguntas preliminares sobre o profissional e a empresa, para a classificação destes e para a análise posterior dos resultados obtidos. Sobre os dados do entrevistado, têm-se: formação, função na empresa e há quanto tempo; sobre a empresa: o setor de atuação, tipos de construção, tempo de existência e número de funcionários. É importante salientar que os dados obtidos, sejam dos entrevistados ou das empresas, são confidenciais.

Em seguida, dividiu-se em duas partes: planejamento estratégico da empresa no geral e planejamento estratégico dos empreendimentos realizados pela empresa. A primeira parte apresenta perguntas sobre como são apresentados e desenvolvidos os objetivos e estratégias na empresa e sobre o planejamento estratégico interno como um todo. E a segunda parte baseou-se no 
trabalho realizado anteriormente por Rotilli (2012), sobre um estudo de caso sobre Planejamento Estratégico em Empresas de Construção Habitacional em Cruz Alta e Ijuí/RS.

Na primeira parte, são 9 perguntas, na qual algumas foram perguntas objetivas, avaliadas por sim, não, pela escala Likert, que apresenta como opção de resposta pontos com descrições verbais que contemplam extremos - "concordo totalmente" e "discordo totalmente" - e outras de múltipla escolha, dependendo da pergunta. Além disso, apenas algumas dessas questões apresentaram abertura para comentários dos entrevistados, haja vista que existe subjetividade e variedade das respostas possíveis. Na segunda parte, são 7 perguntas, na qual algumas foram avaliadas por sim, não, também pela escala Likert e outras de múltipla escolha e apenas algumas dessas questões apresentaram abertura para comentário dos entrevistados. A coleta de dados foi por meio presencial, telefone, email e plataforma online (Google Forms).

\subsection{Perfil das empresas e dos profissionais entrevistados}

Esta pesquisa foi feita com profissionais de algumas empresas no ramo da Engenharia Civil no Maranhão certificadas em nível A pelo PBQP-H (Programa Brasileiro da Qualidade e Produtividade do Habitat). O PBQP-H tem como projeto propulsor o Sistema de Avaliação da Conformidade de Empresas de Serviços e Obras (SIAC), que tem como objetivo avaliar a conformidade do sistema de gestão da qualidade das empresas de serviços e obras, baseando-se na série de normas ISO 9000 (PBQP-h, 2021).

Após a definição do grupo a ser estudado, iniciou-se o contato com profissionais dessas empresas, engenheiros civis, gestores, diretores, donos ou sócios. Ao todo, participaram do trabalho apenas $40 \%$ das empresas previamente selecionadas, pois a maior parte das empresas se recusaram a comentar sobre suas metodologias, alegando que as normas internas não permitiam tais entrevistas. Apesar do número reduzido de empresas que aceitaram responder o questionário, algo já previsto, devido a sensibilidade do tema, a pesquisa continua válida em seu objetivo proposto, inclusive destacando a importância e a necessidade de novos estudos que venham a complementá-lo.

A entrevista teve o intuito de revelar a opinião dos profissionais dessas empresas, obtendo informações sobre o conhecimento e implementação do planejamento estratégico, bem como, os impactos, benefícios e as dificuldades que ele traz, além de contribuir com esse trabalho científico.

Os resultados dessa pesquisa foram analisados através de gráficos e estudos das respostas, que contribuíram, assim, para o entendimento de como é o planejamento estratégico nas empresas.

\section{Resultados e Discussão}

\subsection{Perguntas preliminares}

Buscou-se saber inicialmente um pouco sobre os profissionais e as empresas entrevistadas. Dos entrevistados, 4 são engenheiros civis, 1 engenheiro de produção e 1 administrador. As empresas são dos mais variados ramos da Engenharia Civil: Construção Civil (3), Incorporação (1) e Construção Civil e Incorporação (2)). Quanto aos tipos de Construção, a maioria domina Edificações Residenciais e algumas dominam 2 tipos de construções. O resultado geral encontra-se na figura a seguir: 
Figura 3 - Tipos de construção.

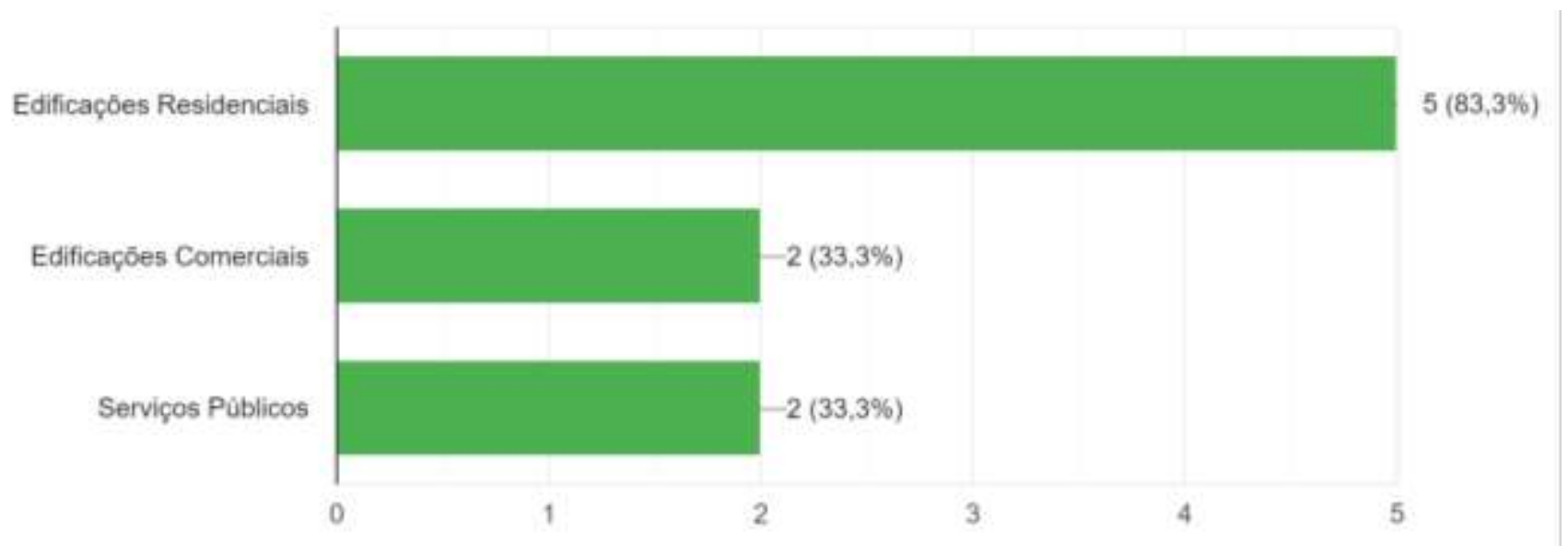

Fonte: Autores (2021).

Através da Figura 3 é possível concluir que a maior parte das empresas entrevistadas trabalha com empreendimentos de edificações residências e nenhuma empresa tem participação em edificações industriais.

Em seguida, foi questionado o tempo de existência das empresas no mercado, como é apresentado na Figura 4:

Figura 4 - Tempo de existência no mercado.

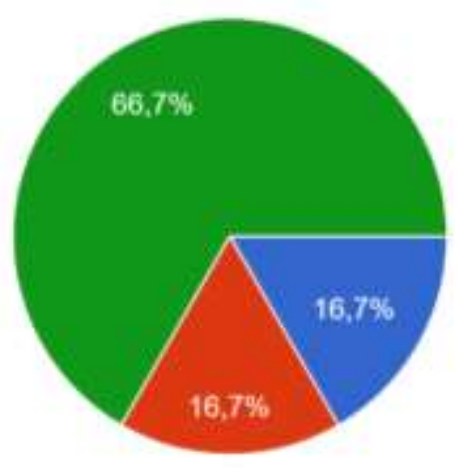

Ate 5 anos

5. 10 anos

$10-15$ anos

Mais de 15 anos

Fonte: Autores (2021).

Como visto na figura acima, quase $67 \%$ das empresas entrevistadas já tem mais de 15 anos de experiência no mercado. Logo, pode-se concluir que o público-alvo escolhido já possui bastante experiência nas áreas de atuação.

\subsection{Perguntas sobre os processos de planejamento das empresas}

Após as perguntas de cunho classificatório, ou seja, perguntas para classificar as empresas quanto seu tempo de experiência no mercado e sua área de atuação, foram realizados os questionamentos a respeito do planejamento interno adotado pelas empresas em seus diversos setores, de que maneira é aplicado e quem participa do processo.

A primeira pergunta visa identificar quais empresas realizam planejamento estratégico, na figura a seguir podemos observar o gráfico que mostra a resposta dos entrevistados. 
Figura 5 - Realização do planejamento estratégico

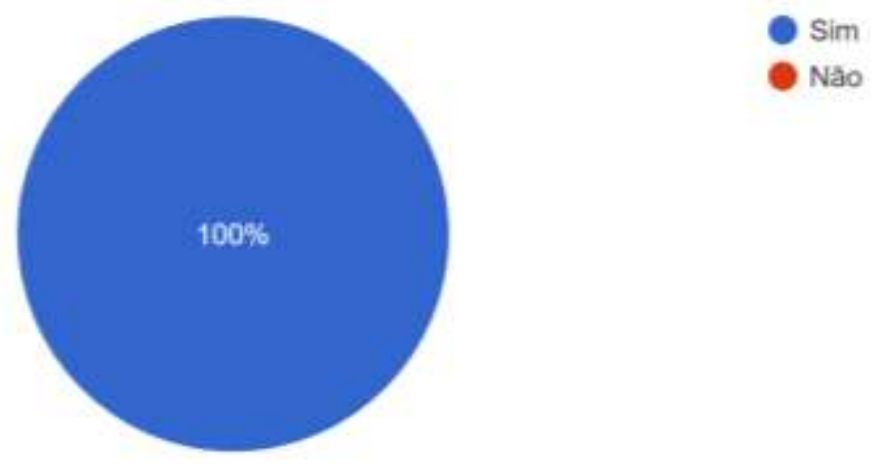

Fonte: Autores (2021).

A figura 5 mostra que $100 \%$ das empresas entrevistadas realizam planejamento estratégico. Esta pergunta teve como objetivo apenas introduzir o entrevistado para as perguntas seguintes, pois os autores já possuíam a informação que todas as empresas entrevistadas realizavam planejamento estratégico, já que o público-alvo desta pesquisa recebeu classificação nível A na avaliação realizada pelo Sistema de Avaliação da Conformidade de Serviços e Obras (SIAC), sendo que um dos requisitos para esta classificação é a realização de planejamento por parte das empresas.

Em seguida, foi questionado quem participava da elaboração do planejamento interno da empresa, a resposta deste questionamento é mostrada na figura a seguir:

Figura 6 - Participantes da elaboração do planejamento

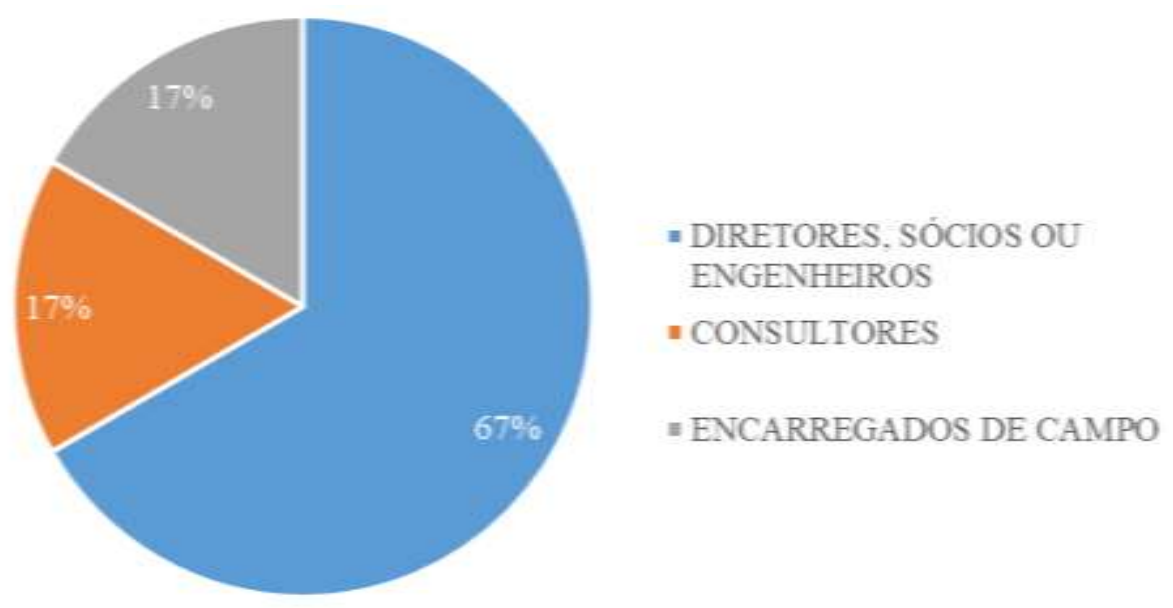

Fonte: Autores (2021).

Apenas 17\% das empresas entrevistadas contratam terceiros para elaboração do seu planejamento e a maior parte das empresas realiza a elaboração do planejamento estratégico com a participação dos diretores e sócios, pode-se concluir que para esse grupo de empresas há prioridade e preocupação com o planejamento da empresa e dos empreendimentos em execução, prova disso é que cada vez mais os líderes buscam implementar e participar dos processos de elaboração dos objetivos de seus negócios. Assim como afirma Paixão e Stadler (2012), o processo de planejar é a principal função de um administrador, pois envolve a criação de um cenário futuro, sendo a base para tomada de decisões.

Em seguida, buscou-se questionar se o planejamento estratégico traz benefícios para a empresa, a resposta está representada na Figura 7. 
Figura 7 - O planejamento estratégico proporciona benefícios para a empresa?

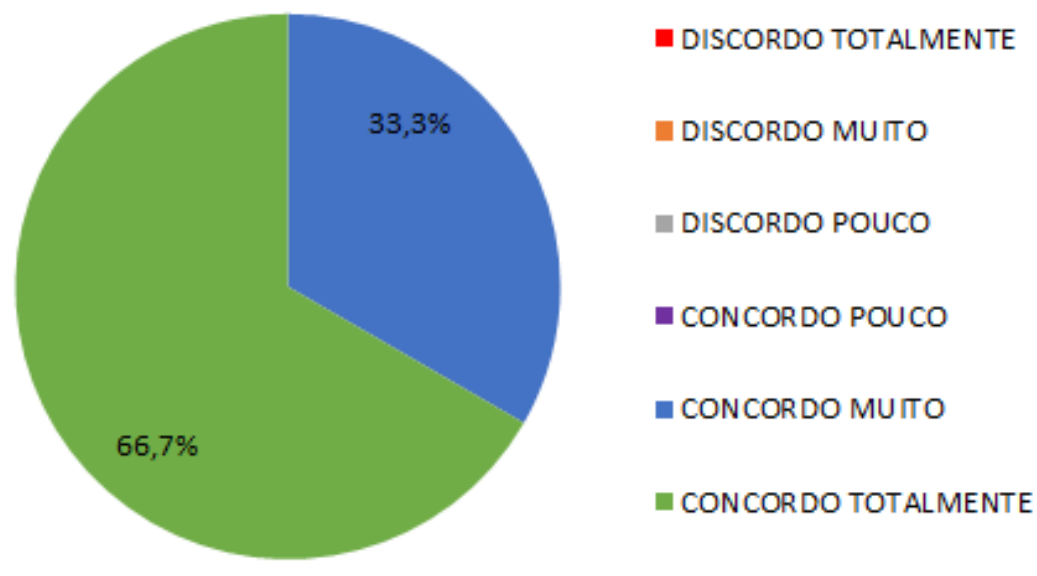

Fonte: Autores (2021).

A pergunta acima foi apresentada como pergunta objetiva de múltipla escolha, porém houve apenas duas respostas marcadas, sendo que todos concordam muito ou totalmente que o planejamento estratégico traz benefícios para a empresa. Todos os entrevistados reconhecem a importância do planejamento estratégico nas metas e objetivos da empresa.

No site da Eaux Consulting, uma empresa de consultoria em gestão empresarial, Rovina (2019) confirma a importância do planejamento estratégico, pois serve como um guia para todas as ações que serão feitas durante um período na empresa, ajudando a administrar a quantidade de tempo, recursos e energia empregada na estratégia. Além disso, também auxilia a reconhecer problemas e identificar melhorias.

Após isso, foi questionado se as estratégias são definidas a partir dos processos críticos da área e se são utilizadas como melhoria na gestão. Apesar da afirmação ser apresentada como objetiva de múltipla escolha, houve apenas duas respostas marcadas.

Figura 8 - Estratégias são definidas a partir dos processos críticos e utilizadas como critérios de melhoria na gestão.

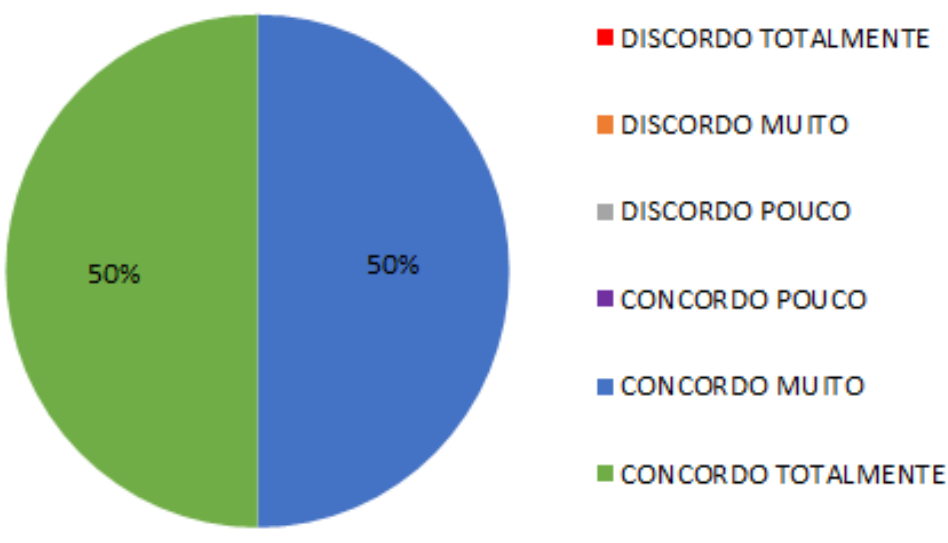

Fonte: Autores (2021).

Quanto a essa pergunta, todos concordam muito ou totalmente que os desafios e dificuldades nos fazem melhorar cada vez mais, principalmente na gestão empresarial, pois como afirma Mattos (2010) quando mais se conhece sobre as dificuldades e os processos críticos é possível realizar a previsão oportuna de situações desfavoráveis, permitindo ao gerente da obra tomar providências a tempo, adotar medidas preventivas e corretivas e tentar minimizar os impactos no custo e no prazo. 
Foi perguntado aos representantes das empresas se os objetivos e as estratégias são comunicados a todos os funcionários e de que maneira são transmitidos, a maioria afirmou que sim, porém, alguns ressaltaram não comunicar ao setor operacional. Além disso, relataram transmitir por meio de reuniões, apresentações e um dos entrevistados mencionou a utilização da plataforma Power BI. Através desta questão é possível entender um pouco dos métodos utilizados internamente.

A pergunta seguinte foi: “As estratégias da empresa buscam interligar todos os setores objetivando agregar valor?". E assim como no questionamento anterior, esta é objetiva de múltipla escolha e novamente houve apenas duas alternativas marcadas. As alternativas estão expostas na figura a seguir.

Figura 9 - As estratégias interligam todos os setores da empresa.

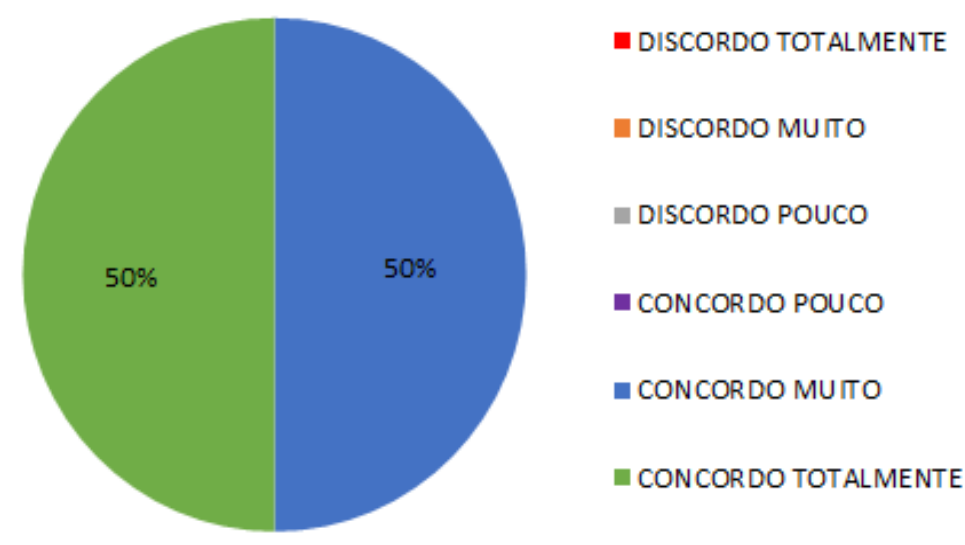

Fonte: Autores (2021).

Todos os entrevistados reconhecem a importância de repassar as estratégias definidas aos diversos setores da empresa, pois como afirma Melo (2006), a comunicação interna, além de favorecer no processo de conclusão dos objetivos, valoriza os funcionários, fazendo com que se sintam necessários e importantes para o cumprimento dos processos e metas da empresa.

A pergunta que vem a seguir procurou saber se as empresas conseguiam seguir o que foi planejado, as respostas estão retratadas na Figura 10 a seguir:

Figura 10 - A empresa segue o planejado?

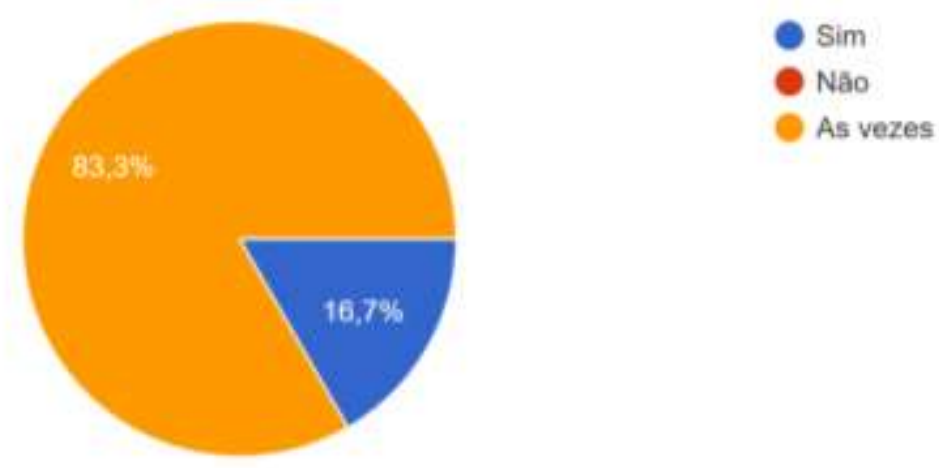

Fonte: Autores (2021).

Esta pergunta se apresentou de forma objetiva e de múltipla escolha, porém para aqueles que responderam negativamente, foi perguntado o porquê de não se conseguir atingir os objetivos almejados. E como quase $84 \%$ dos entrevistados respondeu que apenas às vezes é possível seguir o que foi planejado, estes puderam explicar quais os fatores atrapalham nesses 
processos. As explicações foram diversas, porém a maior parte acredita que os prazos não foram bem definidos ou houve atraso na entrega de material, ou seja, para este grupo de empresas o tempo é o fator que causa maior problemática na execução dos processos.

Em seguida foi questionado aos entrevistados com qual frequência a empresa acompanhava o seu planejamento estratégico. As respostas estão retratadas na Figura 11 a seguir:

Figura 11 - Frequência de acompanhamento do planejamento.

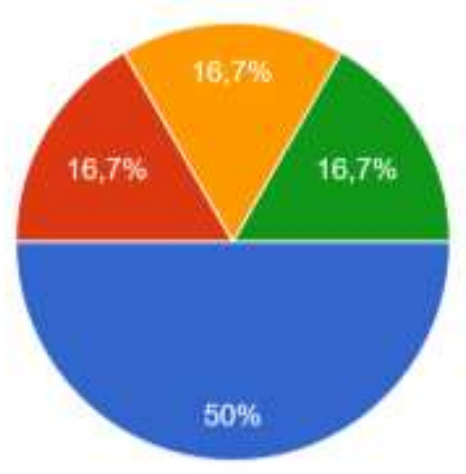

Acompanhamento Mensal

Acompanhamento Semestral

Acompanhamento Anual (de $1 \mathrm{em} 1$ ano)

Acompanhamento Anual (de $2 \mathrm{em} 2$ anos)

Fonte: Autores (2021).

É possível perceber que 50\% das empresas realizam o acompanhamento mensal das suas estratégias, reforçando a importância de sempre estar com os objetivos e metas atualizados de acordo com o ambiente e a situação de cada empresa.

Por fim, em relação aos processos de planejamento nas empresas, foi perguntado como a empresa faz o acompanhamento das estratégias adotadas, as respostas foram diversas, porém a maior parte respondeu que este acompanhamento acontecia através dos indicadores e através do Dashboard estratégico.

Através dos dados obtidos nesta seção e das conversas com os entrevistados, é perceptível que as empresas concordaram em algumas questões, porém houve muitas divergências em relação aos três procedimentos (delineamento, elaboração e implementação) do planejamento estratégico, mostrando assim, que não seguem uma metodologia de forma rigorosa, muitas vezes fazendo-o de maneira informal e empírica. Portanto, quando se fala em metodologias não se tem um manual especificando e listando as mais adequadas para cada empresa, a metodologia é particular, cada empresa tem suas normas de organização, sua maneira de agir e seus processos internos.

\subsection{Perguntas sobre os processos de planejamento dos empreendimentos}

Após as perguntas sobre os processos de planejamento das empresas, foram realizados os questionamentos a respeito do planejamento de seus empreendimentos, de que maneira é aplicado, quem participa do processo e qual tipo de metodologia utilizada.

A primeira pergunta desta seção foi para saber se as empresas elaboravam planejamento estratégico para execução de seus empreendimentos e com que frequência o faziam. As respostas estão retratadas a seguir na Figura 12. 
Figura 12 - Elaboração de planejamento para os empreendimentos

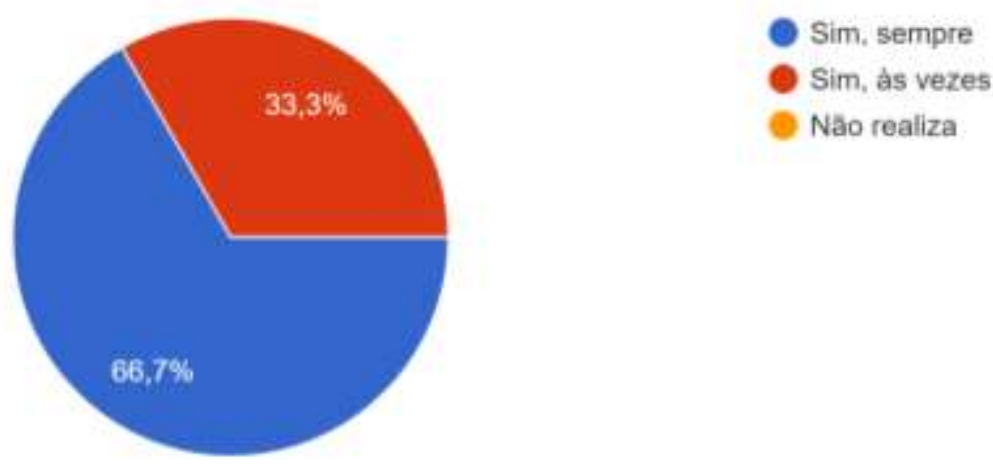

Fonte: Autores (2021).

Aproximadamente $67 \%$ das empresas sempre elaboram o planejamento estratégico de seus empreendimentos, pois sempre visam melhorias na qualidade dos produtos, otimização dos lucros obtidos e diminuição de riscos.

A seguir, questionou-se sobre a importância que as empresas davam ao planejamento de seus empreendimentos e $100 \%$ dos entrevistados responderam que a relevância é primária, sendo uma das fases mais importantes no processo.

Logo após foi perguntado se a empresa desenvolve todo o planejamento antes da execução, ou seja, se ela realiza o estudo preliminar, o estudo de viabilidade, pré-projeto, projeto legal, entre outros. As respostas estão expostas na figura abaixo.

Figura 13 - Desenvolvimento do planejamento antes da execução.

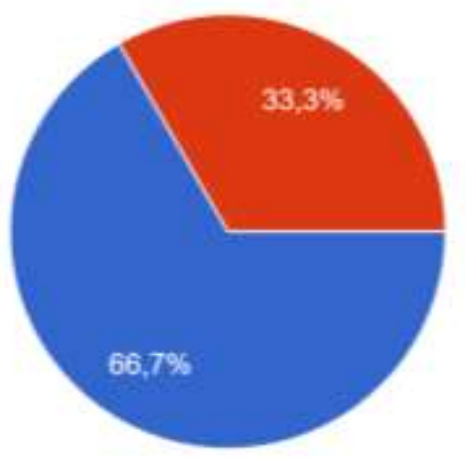

Sim, de forma completa

Sim, mas informalmente

Nào realiza

Fonte: Autores (2021).

Todas as empresas desenvolvem o planejamento antes da execução, sendo que $67 \%$ realizam esse processo de maneira completa, elaborando o estudo preliminar, o estudo de viabilidade, pré-projeto, projeto legal, entre outros. E somente $33 \%$ realizam esse processo de maneira informal.

Foi perguntado também se as empresas realizavam o orçamento de todos os gastos antes da execução do empreendimento e se elaboravam o cronograma de tempo para a realização do empreendimento, a resposta para essas perguntas estão expostas nas Figuras 14 e 15 respectivamente. 
Figura 14 - A empresa realiza um orçamento completo antes da execução do empreendimento.

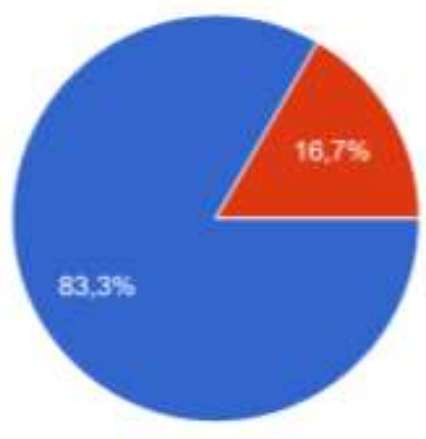

Sim, de forma mais completa possivel

Sim, informalmente

Sim, de forma incompleta

Nấo realiza

Fonte: Autores (2021).

Figura 15 - A empresa elabora o cronograma de tempo antes da execução do empreendimento.

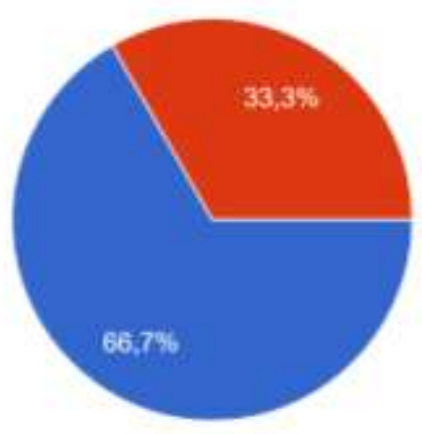

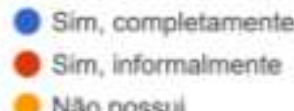

Näo possul

Fonte: Autores (2021).

A respeito da realização de um orçamento completo acerca do empreendimento, observou que todas as empresas o faziam, porém $17 \%$ delas realizava de maneira informal. No que diz respeito à elaboração do cronograma de execução do empreendimento, observou-se que todos o faziam, contudo 33\% dos entrevistados responderam que elaboravam de forma informal. A partir desses dois questionamentos, observou-se que 50\% das empresas entrevistadas elaboram um cronograma físico-financeiro de seus empreendimentos, visto que apenas 50\% elaboram simultaneamente cronograma e orçamento antes da execução e de maneira completa.

A sexta pergunta buscou identificar quem realiza o estudo de viabilidade dos empreendimentos para as empresas, esta pergunta consistiu em uma questão objetiva de múltipla escolha, com as seguintes alternativas: uma pessoa ou equipe especializada dentro da própria empresa; pessoas da direção da empresa sem ser especialistas ou equipe especializada; serviços terceirizados. As respostas estão retratadas na figura a seguir. 


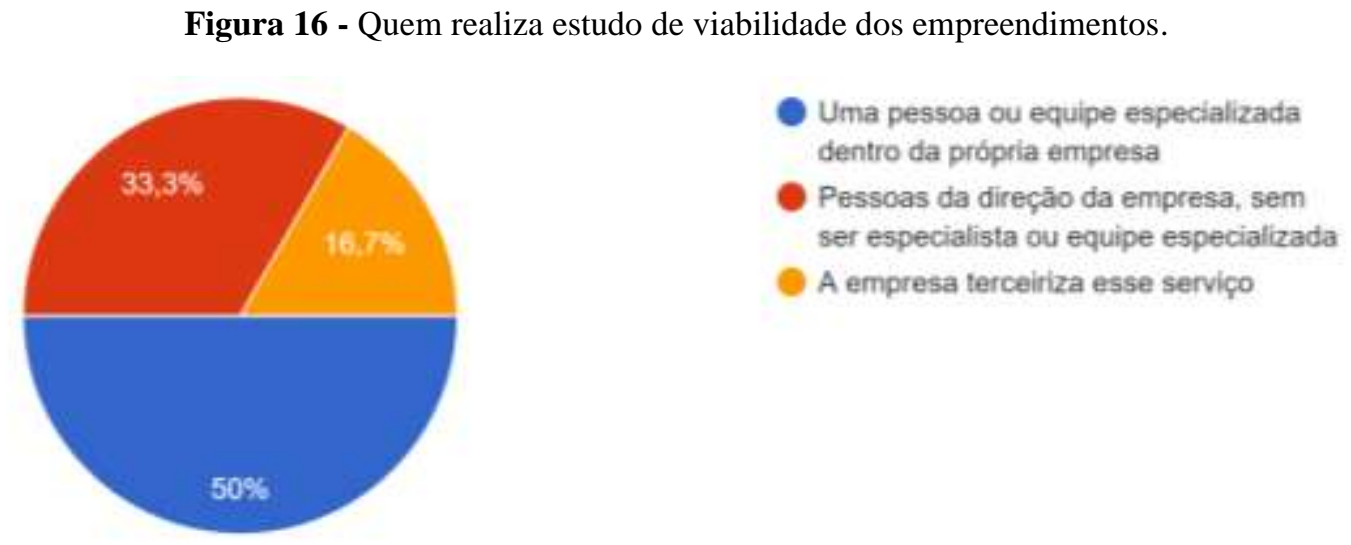

Fonte: Autores (2021).

Estudo de viabilidade é a comparação entre a estimativa de custo do mesmo e os rendimentos que se esperam lucrar por meio da sua comercialização, abrangendo todo planejamento técnico básico necessário, desde a ideia inicial, até a elaboração do anteprojeto (Gehbauer, 2002). Dessa forma percebe-se a importância da realização desse estudo, já que este representa umas das etapas iniciais no momento de escolher um empreendimento. Pode-se concluir que o público entrevistado concorda com as afirmações acima já que a maior parte das empresas respondeu que uma pessoa ou equipe especializada da própria empresa produz o estudo de viabilidade para novos empreendimentos, ressaltando a importância desta etapa no processo de planejamento.

A última pergunta consistiu em: "Quais fatores a empresa acredita que possui como diferenciais na redução de riscos do negócio e facilitação da comercialização?”. Sendo uma questão de múltipla escolha com possibilidade de marcar mais de uma alternativa, as respostas estão representadas na figura abaixo.

Figura 17 - Fatores para redução de riscos e facilitadores na comercialização.

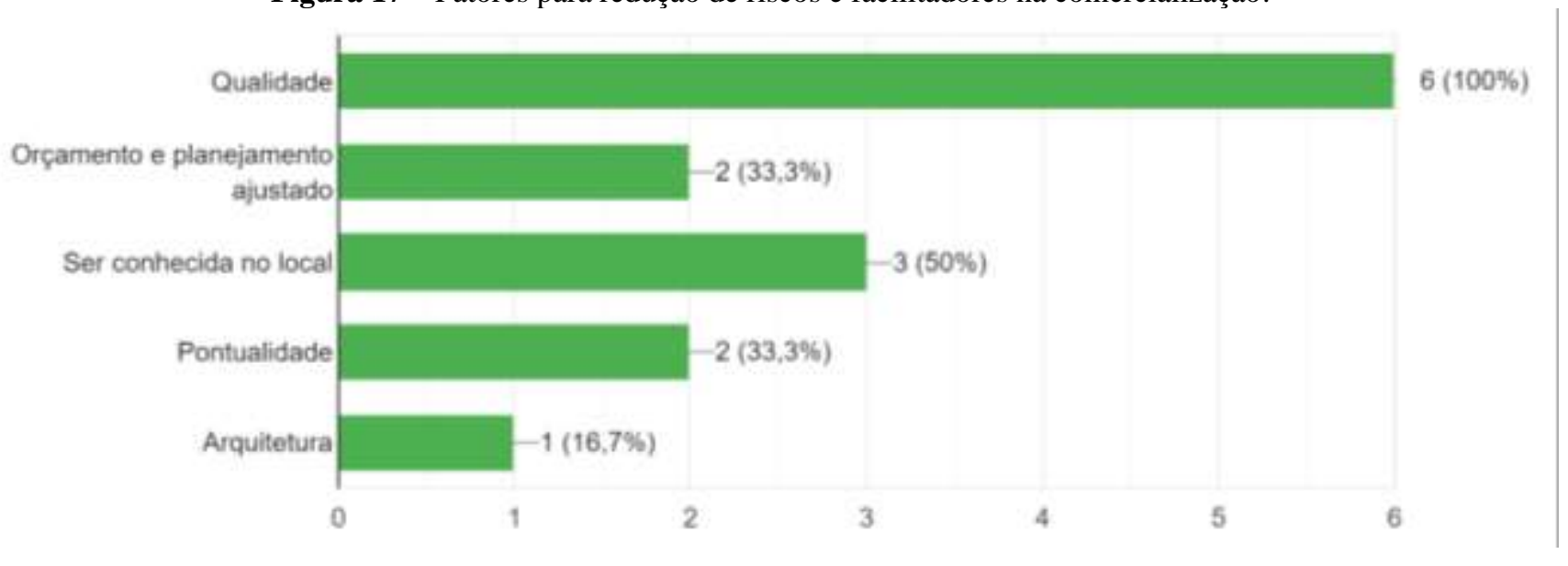

Fonte: Autores (2021).

Todas as empresas afirmaram que a qualidade é o principal fator na facilitação de comercialização e na diminuição de riscos, porém 50\% também afirmaram que a reputação da empresa é importante na venda de novos empreendimentos.

\section{Considerações Finais}

Como exposto na metodologia desta pesquisa, o público-alvo escolhido para as entrevistas foi selecionado a partir da avaliação nível A do SIAC com base no PBQP-H, a pesquisa das empresas foi realizada através da plataforma do próprio site do PBQP-H, a região selecionada foi o estado do Maranhão. Apenas quinze empresas estavam listadas nesses requisitos e só foi 
possível realizar entrevistas com $40 \%$ das empresas selecionadas, ou seja, apenas seis empresas aceitaram participar das entrevistas. Apesar disso, a pesquisa teve resultados satisfatórios já que a maior parte das empresas afirmam realizar os processos de planejamento estratégico, tanto na administração central quanto em seus empreendimentos.

Observou-se que as respostas, durante as entrevistas, convergem em muitos aspectos: utilizam e reconhecem a importância de ter um planejamento estratégico; acreditam que planejar traz benefícios a empresa; e concordam que os processos críticos são os pontos de análise para definir as estratégias e melhorar a gestão. Porém, as respostas divergiram quanto à frequência de acompanhamento do planejamento, visto que variou em mensal, semestral e anual (1 em 1 ano ou $2 \mathrm{em} 2$ anos). E divergem também: quanto ao desenvolvimento do planejamento antes da execução, pois alguns relataram fazê-lo de forma informal, destacando não seguir protocolo; e quanto ao estudo da viabilidade dos empreendimentos em cada empresa é feito por pessoas com funções distintas.

Assim, quando se fala em metodologias de planejamento estratégico não se tem um manual especificando e listando as mais adequadas para cada setor empresarial. Pode-se concluir, a partir dos resultados e das conversas com os entrevistados, que a metodologia é particular, ou seja, cada empresa tem seus métodos de organização, sua maneira de agir e seus processos internos, que visam praticamente os mesmos objetivos, que são alcançar as metas com maior qualidade, maior lucratividade e menores riscos.

Dessa forma, o questionário teve o objetivo de investigar sobre as partes do processo de implementação do Planejamento Estratégico, visto que, em conversas iniciais com os entrevistados, percebeu-se que estes não seguem uma metodologia de planejamento de forma rigorosa e nem procuram por novas ferramentas, acreditando apenas nos processos internos da empresa passados de maneira empírica.

Quanto ao perfil das empresas selecionadas, bem como suas características, constataram-se que em sua maioria o principal responsável pela gestão e pelo planejamento estratégico dos empreendimentos são os proprietários ou diretores, sendo que a maioria destes tem formação em engenharia civil ou em administração de empresas, apenas uma empresa terceirizava esses serviços através da contratação de consultores. Com esta observação, conclui-se que, a gestão das empresas e dos empreendimentos são realizadas por profissionais com competência. Nota-se também, que a maioria das empresas que atuam neste setor tem vasta experiência, pois atuam no ramo há mais de quinze anos. Porém, vale ressaltar que, essa experiência é muito mais prática, adquirida na vivência empresarial, não utilizando muita formalidade e nem tantas técnicas.

Todas as empresas entrevistadas afirmam realizar planejamento estratégico e a maior parte delas alegam informar aos mais diversos setores da empresa, gerando assim, a integralização de todos os funcionários e aumentando a taxa de sucesso dos seus objetivos. Observa-se também que a maioria das empresas respondeu que realiza estudos de viabilidade, controle de custos e execução de cronogramas físico-financeiros, antes do início das obras.

Neste sentido, este estudo além de expor os benefícios da realização e manutenção do planejamento estratégico, pode ser utilizado como referência para desenvolvimento de pesquisas similares, podendo sugerir como estudos, pesquisas entre empresas de diversos ramos, como infraestrutura e engenharia industrial e ainda, ampliar o público-alvo para aquelas empresas que não possuem o nível A na avaliação do SIAC.

\section{Referências}

Alday, H. E. C. (2000). Planejamento Estratégico Dentro do Conceito de Administração Estratégica. Revista FAE. https://revistafae.fae.edu/revistafae/artic le/view/505/400

Arruda, L. L. \& Voese, S. B. (2009). Utilização de ferramentas gerenciais e controle de custos nas organizações do terceiro setor: estudo nas Redes Metrológicas estaduais. XVI Congresso Brasileiro de Custos. Fortaleza. https://anaiscbc.emnuvens.com.br/anais/article/viewFile/967/967

Associação Brasileira de Normas Técnicas. NBR 10520. (2002). Informação e documentação - Citações em documentos - Apresentação. Rio de Janeiro.

Associação Brasileira de Normas Técnicas. NBR 14724. (2016). Informação e documentação - Trabalhos acadêmicos - Apresentação. Rio de Janeiro. 
Research, Society and Development, v. 10, n. 9, e27910918240, 2021

(CC BY 4.0) | ISSN 2525-3409 | DOI: http://dx.doi.org/10.33448/rsd-v10i9.18240

Associação Brasileira de Normas Técnicas. NBR 6024. (2003). Informação e documentação - Numeração progressiva das seções de um documento Apresentação. Rio de Janeiro.

Associação Brasileira de Normas Técnicas. NBR ISO 9001. (2015). Sistema de gestão da qualidade - Requisitos. Rio de Janeiro.

Chagas, L. R. B. (2008). Engenharia da construção: obras de grande porte. Pini/Odebrecht. https://www.passeidireto.com/arquivo/20389705/engenharia-daconstrucao-luiz-roberto-batista-chagas

Francisco, A. C., Oliveira, A. C. \& Pagani, R. N. (2011). Diagnóstico estratégico aplicado em uma empresa de transportes agrícolas. Universidade Tecnológica Federal do Paraná. Curitiba.

Gehbauer, F. (2002). Planejamento e Gestão de Obras. Editora CEFET - PR. Curitiba.

Lima, A. A. (2009). Planejamento Estratégico: uma ferramenta eficaz para tomada de decisão. Dissertação (Graduação) - Escola de Guerra Naval. Rio de Janeiro. http://www.redebim.dphdm.mar.mil.br/vinculos/00000c/00000cd2.pdf

Marconi, M. D. \& Lakatos, E. M. (2003). Fundamentos da metodologia científica. Atlas.

Mattos, A. D. (2010). Planejamento e controle de obras. Pini. São Paulo.

Melo, V. P. C. (2006). A comunicação interna e sua importância nas organizações. Tecitura.

Mendes, G. H. S. (2015). Administração estratégica. Florianópolis: Universidade Federal de Santa Catarina - UFSC. http://www.profiap.org.br/profiap/sobreo-curso/guias-didaticos/profiap-administracao-estrategica-final.pdf

Moreira, M. \& Bernades, S. (2001). Desenvolvimento de um Modelo de Planejamento e Controle da Produção para Micro e Pequenas Empresas de Construção Dissertação (Doutorado) - Universidade Federal do Rio Grande do Sul. https://www.lume.ufrgs.br/bitstream/handle/10183/13718/0 00292771.pdf?sequence=1

Oliveira, D. P. R. (2007). Planejamento Estratégico: conceitos, metodologia e práticas. Atlas (23a ed.).

Oliveira, D. P. R. (2018). Planejamento Estratégico: conceitos, metodologia e práticas. Atlas (34a ed.). Atlas.

Paixão, M. V. \& Stadler, A. (2012). Modelos de gestão. Instituto Federal do Paraná.

Pereira, M. F. (2002). A Construção do Processo de Planejamento Estratégico a Partir da Percepção da Coalização Dominante. Dissertação (Doutorado) Universidade Federal de Santa Catarina - UFSC. Florianópolis. https://core.ac.uk/download/pdf/30364622.pdf

Pereira, M. F. (2011). Administração Estratégica. Florianópolis: Universidade Federal de Santa Catarina - UFSC. http://www.ead.uepb.edu.br/ arquivos/licitacao_livros_admpub/16-administra\%E7\%E3o\%20estrat\%E9gica/livro\%20administra\%E7\%E3o\%20estrat\%E9gica.pdf

Programa Brasileiro da Qualidade e Produtividade do Habitat. (2021). Sistema da avaliação de serviços e obras - Siac. http://pbqph.mdr.gov.br/projetos_siac.php

Ribas, A. J. F., Facine, M. A. \& Teixeira, G. (2014). Planejamento Estratégico. Unicentro.

Rigby, D. K. (2009). Ferramentas de Gestão: um Guia para Executivos. Bain \& Company, Inc. https://www.profrandes.com.br/userf iles/d69bcc9f0eb9452f3afef3a9b408ac22.pdf

Rotilli, L. (2012). Planejamento Estratégico em Empresas de Construção Habitacional: Estudo de Caso em Cruz Alta e Ijuí/RS. Dissertação (Graduação) Universidade Regional do Noroeste do Estado do Rio Grande do Sul. Ijuí. http://docplayer.com.br/16132680-Universidade-regional-do-noroeste-do-estado-dorio-grande-do-sul.html

Rovina, J. (2019). Planejamento Estratégico: entenda como criar e gerenciar a estratégia da sua organização. https://www.euax.com.br/2019/01/planejamentoestrategicol

Teixeira, C. A. C., Dantas, G. G. T. \& Barreto, C. A. (2015). A importância do Planejamento Estratégico para pequenas empresas. Revista Eletrônica e Científica da FAESB. Tatuí 